\title{
FREQUENCY OF INTESTINAL TUBERCULOSIS IN CASES OF INTESTINAL OBSTRUCTION
}

\author{
Khalid Ahsan Malik and Irshad Waheed
}

\begin{abstract}
OBJECTIVE: To determine the frequency of intestinal tuberculosis in cases of intestinal obstruction.

DESIGN: A descriptive, case review.

SETTING: Jinnah Postgraduate Medical Centre, Karachi - Sindh, from September 1988 to September 1994.

METHODS: Total five hundreds and ninety-two patients of intestinal obstruction were operated during study period. Out of these, ninety-three were found to have intestinal tuberculosis on histopathology. All these patients were admitted through Accident \& Emergency or out-patient departments.

RESULTS: Among ninety-three cases found to have intestinal tuberculosis; they included fiftyone females and forty-two male patients. Age varied from 12 to 68 years. Majority of patients was in second and third decades. Patients presented with asthenia, nausea, vomiting, fever, night sweats and weight loss. Forty-three patients, out of ninety-three had peritonitis. Exploratory laparotomy was performed in all cases. The site of gut involved was jejunum, terminal ileum and ileocaecal junction. However, ileum was found most frequently affected site in $\mathbf{5 1 . 6 1 \%}$ cases. Operative findings inlcuded perforation of gut and mass in ileocaecal region in $\mathbf{3 0 . 2 7 \%}$ cases each. Right hemicolectomy was performed in 45 (48.60\%) cases followed by resection anastomosis in 24(25.72\%), ileostomy in 15 and repair of perforation in 9 cases. Antituberculous therapy was given to all these patients. Mortality was $10 \%$ in these cases.

CONCLUSION: Patients with intestinal obstruction, presenting with fever, loss of weight, nausea, and night sweats should be considered as intestinal tuberculosis until and unless proved otherwise. Laparotomy and histopathology are important for diagnosis and treatment of these cases.
\end{abstract}

KEY WORDS: Intestinal tuberculosis. Intestinal obstruction. Biopsy.

\section{INTRODUCTION}

Tuberculosis is a major public health hazard and is the leading cause of death in Pakistan. ${ }^{1}$ It infects one-third of world population and kills about three million people each year. ${ }^{2}$ Pulmonary tuberculosis is the most important form as it is responsible for spread of tuberculosis in community. It is very important that no efforts should be spared to diagnose and treat tuberculosis ${ }^{3}$ to avoid complication of intestinal tuberculosis like intestinal obstruction, bowel perforation leading to peritonitis, bleeding and enterocutaneous fistulas. Intestinal obstruction is the most common complication of intestinal tuberculosis. ${ }^{4-7}$ Poverty, overcrowding and unhygienic conditions are making the situation worse in underdeveloped countries and are responsible for spread of the disease. ${ }^{8}$ Therefore, it is important that every effort should be made to timely diagnose and treat the disease, and prevent and control the mortality. Hence, this study was planned to find out the frequency of intestinal tuberculosis in operated cases of intestinal obstruction in our set up.

\section{PATIENTS AND METHODS}

This study was conducted at Jinnah Postgraduate Medical Centre, Karachi - Pakistan. Total five hundred and ninety-two patients of intestinal obstruction were operated from September 1988 to September 1994 and out of these, ninety-three cases were found to have intestinal tuberculosis on histopathology. Data were collected through a pre-designed proforma. All the patients were admitted through Accident \& Emergency or out patients department. 


\section{RESULTS}

Total five hundred and ninety-two patients of intestinal obstruction were operated during study period. Out of these, ninety-three had intestinal tuberculosis, found on histopathology. These included fifty-one females and forty-two male patients. Age of patients ranged from 12 to 68 years. However, majority of patients were in second and third decades of their life (Table I). Patients presented with asthenia, nausea, vomiting, fever, night sweats and weight loss. Forty-three patients out of ninety-three were found to have peritonitis. Exploratory laparotomy was performed in all these patients. The sites of gut involved included jejunum, terminal ileum and ileocaecal junction (Table II). Operative findings were ileocaecal mass, stricture, adhesions and perforation of small gut (Table III). Procedures performed were stricturoplasty, right hemicolectomy, resection of the affected gut and end ileostomy (Table IV). Anti-tuberculous therapy was given to all these patients. Mortality in this study was $10 \%$.

TABLE I:

AGE AND SEX DISTRIBUTION OF CASES

\begin{tabular}{|l|c|c|c|}
\hline $\begin{array}{c}|c| \\
\text { (in years) }\end{array}$ & MALE & FEMALE & $\begin{array}{c}\text { PERCENT- } \\
\text { AGE }\end{array}$ \\
\hline $12 \_20$ & 18 & 26 & $(47.29 \%)$ \\
\hline $21 \_30$ & 10 & 14 & $(24.78 \%)$ \\
\hline $31 \_40$ & 08 & 08 & $(17.09 \%)$ \\
\hline $41 \_50$ & 05 & 03 & $(07.59 \%)$ \\
\hline $51 \_$above & 01 & 02 & $(03.25 \%)$ \\
\hline
\end{tabular}

TABLE II:

INTESTINAL INVOLVEMENT OF CASES

\begin{tabular}{|l|c|c|}
\hline \multicolumn{1}{|c|}{ SITE } & NUMBER & PERCENTAGE \\
\hline lleum & 48 & $51.61 \%$ \\
\hline lleocaecal region & 30 & $32.27 \%$ \\
\hline Both ileum, jejunum & 11 & $11.82 \%$ \\
\hline Jejunum & 04 & $04.30 \%$ \\
\hline
\end{tabular}

TABLE III:

OPERATIVE FINDINGS IN CASES

\begin{tabular}{|l|c|c|}
\hline \multicolumn{1}{|c|}{ FINDING } & NUMBER & PERCENTAGE \\
\hline Mass in ileocaecal region & 30 & $32.27 \%$ \\
\hline Perforation & 30 & $32.27 \%$ \\
\hline Strictures & 18 & $19.35 \%$ \\
\hline Adhesion & 15 & $16.11 \%$ \\
\hline
\end{tabular}

TABLE IV:

SURGICAL PROCEDURS PERFORMED IN CASES

\begin{tabular}{|l|c|c|}
\hline \multicolumn{1}{|c|}{ PROCEDURE } & NUMBER & PERCENTAGE \\
\hline Right hemicolectomy & 45 & $48.60 \%$ \\
\hline Resection anastomosis & 24 & $25.72 \%$ \\
\hline Ileostomy & 15 & $16.01 \%$ \\
\hline Repair of perforation & 09 & $09.67 \%$ \\
\hline
\end{tabular}

\section{DISCUSSION}

Intestinal tuberculosis is one of the common problems faced by surgeons in the developing world. It affects most commonly the young adults in $2^{\text {nd }}$ and $3^{\text {rd }}$ decades. $^{8-11}$ In this study, most of the patients were also in $2^{\text {nd }}$ and $3^{\text {rd }}$ decades of the life. More females were affected as compared to males in this study where female patients were fifty-one and males were fortytwo. Same findings have been reported in other studies. ${ }^{11-13}$ Fifteen percent of patients presented with intestinal obstruction due to tuberculosis in this study, however one other study from Pakistan has reported $11 \%$ cases of intestinal obstruction due to tuberculosis. ${ }^{14}$ Male predominance has also been found in some studies. ${ }^{12,15}$ Exploratory laparotomy was performed in all cases. Intestinal obstruction due to tuberculosis was found in ninety-three patients. It was found that eighteen patients had strictures involving terminal ileum while thirty patients had ileocaecal mass. Perforation was present in thirty patients and fifteen patients were having adhesions. These findings are comparable with other studies. ${ }^{11,12,16-18}$ In this study, right hemicolectomy was done in forty-five cases, ileostomy in fifteen patients, resection anastomosis in twenty-four patients and repair of perforation in nine patients. Adhesiolysis was also performed in two cases. Mortality in this study was $10 \%$ and this figure is comparable with other studies in which it is reported from $6 \%$ to $50 \%$. $^{5,10,19,-22}$

\section{CONCLUSION}

Intestinal tuberculosis is a major health problem in our part of the world. Patients of intestinal obstruction presenting with fever, loss of weight, nausea, and night sweats should be considered as cases of intestinal tuberculosis until and unless proved otherwise. Laparotomy and histopathology are important in the diagnosis and treatment of such cases.

\section{REFERENCES}

1. Aziz A. Tuberculosis control program in West Pakistan. Proceedings of the $7^{\text {th }}$ Asia Pacific Congress on Diseases of Chest. Hong Kong, Nov. 1981, 1947-8. 
2. Khushk IA, Ahmed I, Shah SS. Tuberculosis control in Pakistan: current issues and challenges. J Coll Physicians Surg Pak. 2006;16(6):387-8.

3 . Tuberculosis treatment guidelines for national programmes. World Health Organization. Geneva, 1993.

4. Das $P$, Shukla HS. Clinical diagnosis of abdominal tuberculosis. Br J Surg. 1976; 63:941-6.

5. Bhansali SK. Abdominal tuberculosis. Ann Gastroenterol. 1977;67:324-37.

6. Paustran FF, Bockas H. So-called primary ulcerohypertropic ileocaecal tuberculosis. $\mathrm{Br}$ Med $\mathrm{J}$. 1959;27:509-18.

7. Paustran FF, Marshall JB. Intestinal tuberculosis in gastroenterology. $4^{\text {th }}$ ed. Philadelphia, WB Saunders. 1985: Pp.2018-36.

8. Amber $\mathrm{G}$. The reappearance of abdominal tuberculosis. Surg Gynecol Obstet. 1991;172: 432.

9. Manohar A. Symptoms and investigative findings in 145 patients with tuberculous peritonitis diagnosed by peritoneoscopy and biopsy over a five years period. J Surg. 1996;11-12: 38-40.

10. Hulnick DH. Abdominal tuberculosis; CT evaluation. Clin Radiol. 1985;157:99.

11. Taj M. Experience with abdominal tuberculosis. J Postgrad Med Inst. 1988;12:72-80.

12. Baluch N. Abdominal tuberculosis; a varied presentation. Pak J Surg. 1993;9(1):8-12.
13. Wilfred. The varied clinico-radiological presentation of abdominal tuberculosis. Asian Med $\mathrm{J}$. 1989;32(2):99-108.

14. Maqbool. lleocaecal tuberculosis; a study of 31 cases. Pak J Gastroenterol. 1998;12(1-2):45-50.

15. Meekim K. Intestinal tuberculosis; clinicopathologic analysis and diagnosis by endoscopic biopsy. Am J Gastroenterol. 1998; 93(4): 606-9.

16. Sadiq M. Intestinal tuberculosis, surgical aspects. J Postgrad Med Inst. 1997;11(1):29-33.

17. Jamil A, Zafar M. Abdominal tuberculosis; PIMS experience. J Pak Inst Med Sci. 1996; 11-12:3840.

18. Harkvath KD. Intestinal tuberculosis, return of an old disease. Am J Gastroenterol. 1998;(5):692-6.

19. Fakhir H. Abdominal tuberculosis in Saudi Arabia: a clinico-pathological study of 65 patients. Ann Gastroenterol. 1993; 88(1): 75-79.

20. Silicar Tanija VA. Epidemiology and clinical presentation of abdominal tuberculosis: a retrospective study. J Int Med Assoc. 1996; 94(9): 342.

21. Wells D. Abdominal tuberculosis, still a problem today. J R Soc Med. 1986;79:149.

22. Rajput MJ, Memon AS, Rani $S$ and Memon $A H$, Clinicopathological profile and surgical management outcomes in patients suffering from intestinal tuberculosis. J Liaquat Uni Med Health Sci. 2005; 4(3): 100-104.

AUTHOR AFFILIATION:
Dr. Khalid Ahsan Malik (Corresponding Author)
Associate Professor
Department of General Surgery
Civil Hospital and Dow University of Health Sciences,
Karachi, Sindh - Pakistan.
Prof. Irshad Waheed
College of Physicians and Surgeons Pakistan,
DHA Phase II, 7th Central Street - Karachi, Pakistan.

